\title{
Acceptability of Oral-fluid rapid HIV 1 and 2 antibody test among selected key populations in Sri Lanka
}

\author{
Karawita D.A. ${ }^{1}$, Tennakoon S.U.B. ${ }^{2}$, Suranga S. ${ }^{3}$, Dissanayake M.S.W. ${ }^{4}$
}

\begin{abstract}
Introduction: Oral-fluid rapid HIV 1 and 2 antibody test is recommended by WHO to be used as a "test for triage" to support expanding community-based HIV testing services among Key populations (KPs) for HIV infection such as Men who have sex with men (MSM), Beach boys (BB), Female sex workers (FSW) and Drug users (DUs)

Objective: The aim of this study was to ascertain the acceptability of oral fluid rapid HIV $1 / 2$ antibody test $\left(\right.$ OraQuick $^{\circledR}$ ) among key populations receiving services under the Global Fund HIV prevention project during 2013-2015 in Sri Lanka.

Methods: Out of the total registered members of KPs $(21,014)$, a purposive sample of 614 (MSM185, BB-128, FSW-155, DU-146) was studied. Data collected by WHO certified community testers using three tools, i). interviewer administered questionnaire, ii) confidential oral fluid rapid HIV test and recording, iii), a self-administered feedback form.

Results: Mean age of the sample was 34 years ( $M d n=32.7$ years). Males, females and transgender people were $68.9 \%, 30.6 \%$, $0.5 \%$ respectively. Further, $40.7 \%$ were single, $36.5 \%$ married, $11.7 \%$ living together and $11 \%$ were separated. It seems that these groups prefer both community testing $(49 \%)$ as well as outreach testing by STD staff (49\%). However, going to an STD clinic was preferred only by $10 \%$. Majority preferred oral-fluid testing $(88 \%)$ and finger prick testing preferred by $10.2 \%$. Majority expected test report just after the test (88.3\%). The overall satisfaction of the oral-fluid rapid HIV test by KPs was MSM 97\%, BB-99\%, FSW-99\%, DU-99\%.
\end{abstract}

Conclusions: Members of KP groups show high level of acceptability for the oral-fluid rapid HIV 1 and 2 antibody test. This type of "test for triage" approach can be used to improve the community based HIV testing in Sri Lanka.

Key words: HIV, oral fluid test, Acceptability, Sri Lanka

Authors: corresponding author; ${ }^{1}$ Dr D. Ajith Karawita, MBBS, PgD Ven, MD, FSLCoSHH, Consultant Venereologist, Teaching Hospital, Anuradhapura, Sri Lanka. Email: ajith.karawita@gmail.com, (D) https://orcid.org/0000-0003-2956-8479

${ }^{2}$ Dr S. U. B. Tennakoon, MBBS, MPH, M.Phil, PhD, Senior Lecturer, Department of Community Medicine, University of Peradeniya.

Email: sampathte@yahoo.com, (iD https://orcid.org/0000-0002-0648-614X

${ }^{3}$ Mr M. Suchira Suranga, B.Sc(Sp) Hons, M.Sc, M.Phil, Head of, Monitoring and Evaluation, Family Planning Association of Sri Lanka. Email: suchirasuranga@gmail.com, (D) https://orcid.org/0000-0002-8200-9572

${ }^{4}$ Ms Madusha S. W. Dissanayake, B.Sc, Dip IR, Dip HP. M.Sc (Anthropology), Director, Public Affairs, Policy \& Advocacy, Family Planning Association of Sri Lanka.

(c) (i)

Conflict of interest: Authors claim no conflicts of interest, Funding: Multi Country South Asia Global Fund (GF-MSA) Programme under the purview of UNDP Bangkok, Regional Hub, Originality: This is an original work and the findings were orally presented at the National Health Research Symposium 2017 at the session number 10, titled "Diagnostics", held at BMICH, Sri Lanka Submitted: 11.12.2017, Accepted: 15.12.2017 


\section{Full article}

\section{Introduction}

Sri Lanka is a country with low level of HIV epidemic. HIV prevalence has not consistently exceeded $5 \%$ in any of the key populations such as female sex workers (FSW), men who have sex with men (MSM), and drug users (DU). A cumulative total of 2308 HIV positive persons have been reported up to end 2015. During 2015, total of 235 HIV cases reported to the National STD/AIDS Control Programme (NSACP). In general, an estimate of 10.5 new infections occurs per week out of which, only about 4.5 new cases are reported to the NSACP. HIV prevalence in the general population is $0.02 \%$. (1)

Sri Lanka has completed a phase of HIV prevention project from 2013 through 2015 under the support of Global Fund. During this period, HIV prevention interventions were mainly targeted at key populations (KP). The intervention included a delivery of HIV prevention package (HPP) to men who have sex with men (MSM), beach boys (BB), female sex workers (FSW), and drug users (DU). The services in the HPP is shown in Box 1.

Box 1: HIV prevention package (HPP)

1. Provision of STI knowledge,

2. Provision of HIV knowledge,

3. Provision of key population tailored leaflets,

4. Condom/dildo demonstration,

5. Provision of condoms and

6. Escorting of peers to STD clinic for HIV testing.

Those who received all 1 to 5 services in the HPP are defined as "reached". Once the reached person is escorted to a STD clinic, they are defined as "escorted".

This HPP was delivered to KPs through peer educators (PE) scattered in selected districts in the country. Each PE has regular contact with another 6-15 peers forming a peer group (PG). Total of 1,284 peer groups (PG) were operational at the end of 2015 (MSM 382, BB 116, FSW 374, DU 412).

However, in this model, approximately $60 \%$ of key populations in the project do not take the escorting step for HIV testing. In this background, a national steering committee was formed to introduce an oral-fluid rapid HIV antibody test as a community based testing model to Sri Lanka. The committee decided to test its acceptability in a research model among those currently in the peer group intervention.

In the recently released WHO consolidated Guidelines on HIV Testing Services introduces a strategy to support expanding communitybased HIV testing services (HTS), particularly to reach higher risk populations who may not otherwise test for HIV and link to prevention, treatment and care. (2) Test for triage is an approach to support community-based HTS provided by lay community providers. In this approach, trained and supported lay providers conduct an HIV rapid diagnostic test (RDT) and if reactive, the individual is promptly linked to a facility for further HIV testing where the validated national testing algorithm is performed. (2)

Therefore, the objective of the study is to ascertain the acceptability of Oral-fluid rapid HIV $1 / 2$ antibody test (OraQuick) among key populations receiving services under GFATM HIV prevention project in Sri Lanka

\section{Methods}

Study design: descriptive cross sectional study among selected members of key population groups in Sri Lanka

Study setting: Sri Lanka has completed a phase of HIV prevention activity plan under the Global Fund to Fight AIDS, Tuberculosis and Malaria (GFATM) during 2013 to 2015 period which is currently continued for another 3-years under the New Funding Model (2016-2018) of GFATM.

The Family Planning Association of Sri Lanka as the non-governmental principal recipient of the GFATM grant is currently carrying out HIV prevention interventions for KPs through peer groups. Under this model, peer educators, who were persons identified as having knowledge and leadership qualities, were trained and a monthly allowance was given to 
maintain an average of 8 peers (range, 1-26) forming a peer group and the model was supervised and coordinated by the other staff of the project

There were total of 1,284 peer groups (MSM 382, BB 116, FSW 374, DU 412) scattered in 13 districts in Sri Lanka covering a total peer population of 21,014.

Population: All the peers of key populations over 18 years of age and registered under the Global Fund HIV prevention project (20132015) and those received services were included as the population. (table 1 )

Sample: A purposive sampling method was used to take sub-set of peer population. Table 1 , shows the different population sizes under each key population groups and the size of the purposive sample.

Table 1. Distribution of population sizes and samples by key population groups

\begin{tabular}{|l|r|r|r|r|r|}
\hline Category & MSM & BB & FSW & DU & Total \\
\hline $\begin{array}{l}\text { Peer } \\
\text { population }\end{array}$ & 4,746 & 2,047 & 5,392 & 8,829 & 21,014 \\
\hline Sample size & $\mathbf{1 8 5}$ & $\mathbf{1 2 8}$ & $\mathbf{1 5 5}$ & $\mathbf{1 4 6}$ & $\mathbf{6 1 4}$ \\
\hline
\end{tabular}

Data collection: Data collection for the study was done using following three tools

- Interviewer administered questionnaire; Questionnaire was developed in English in consultation with community groups and experts and then translated to local languages Sinhala and Tamil and pretested among a group of key populations.

- Performance of oral-fluid rapid HIV test; for this OraQuick ${ }^{\circledR}$ HIV-1/2 rapid antibody test was used, it is a qualitative immunochromatographic test for the detection of HIV 1 and 2 antibodies (Manufactured in Thailand for OraSure Technologies, Inc.). It has sensitivity of $100 \%$ and specificity of $99.87 \%$ (3)

- Self administered feedback form; was also developed using literature, and in consultation with subject and community experts in English language and then translated to local language Sinhala and
Tamil. Feedback form was pre-tested among a group of KPs.

Data were collected from- $10^{\text {th }}$ August, 2016 to $28^{\text {th }}$ October, 2016 by trained research assistants representing both community and non-community groups.

Training of research assistants: A Mixed group of individuals representing community and non-community groups were trained in a three day residential programme. All were trained to become WHO certified community testers. The training programme was conducted by an international consultant with the help of local consultants.

Data collection process: First, the study information sheet was given to study participants to read and understand or was read to participants who were illiterate. Then, informed consent was taken for the questionnaire and the oral-fluid HIV test. Participants were interviewed in a private and a confidential setting to complete the questionnaire. Then oral-fluid rapid HIV test was performed by gently swiping the test swab along upper and lower gums. Then the swab was inserted to a test tube provided with the test pack and results were read in 20 minutes and recorded. Participants were given pre- and post HIV test counseling. After the HIV test, participants were given a self administered feedback form as the final step of the data collection process.

Data analysis: All the qualitative variables were analyzed for frequencies and percentages for individual peer type (FSW, MSM, BB, DU). Percentages for the whole sample were adjusted by calculating weighted averages proportionate to the size of the population. Quantitative variables were analyzed for central tendency and variability (Range or Standard Deviation). The stakeholders wanted to have one summary measure for all four key populations. In this context, weighted average of four estimates was considered as a more reliable estimate for all key populations. Weights were given 
considering the size of the peer population

(MSM - 4746, BB-2047, FSW-5392, DU-8829).

\section{Ethical considerations}

Ethics clearance was taken from the Ethical Review Committee (ERC) of the Faculty of Medicine, University of Peradeniya on 21.07.2016 (project No. 2016/EC/31)
All the potential participants completed the questionnaire and the oral-fluid rapid HIV test and no withdrawals reported during the phase of the completion of the study.

Sample characteristics: Table 2 indicates the sample characteristics by different type of peer groups of key populations studied.

Results

Table 2: Sample characteristics

\begin{tabular}{|c|c|c|c|c|c|c|c|c|c|c|}
\hline \multicolumn{11}{|c|}{ Mean and Median age by peer type } \\
\hline & & \multirow{2}{*}{\multicolumn{2}{|c|}{$\begin{array}{r}\text { MSM } \\
29.78(9.09)\end{array}$}} & & BB & & FSW & & DU & Total (ADJ) \\
\hline \multirow[t]{2}{*}{ Age (Years) } & Mean (SD) & & & \multicolumn{2}{|c|}{$30.88(11.84)$} & \multicolumn{2}{|c|}{36.36 (10.64) } & \multicolumn{2}{|c|}{$36.41(11.84)$} & 34.36 \\
\hline & Median (Range) & \multicolumn{2}{|c|}{$28(18-68)$} & \multicolumn{2}{|c|}{$28(18-69)$} & \multicolumn{2}{|c|}{$35(18-65)$} & \multicolumn{2}{|c|}{$35(18-67)$} & 32.74 \\
\hline \multicolumn{11}{|c|}{ Socio-demographic characteristics } \\
\hline \multirow[t]{2}{*}{ Category } & \multirow[t]{2}{*}{ Level } & \multicolumn{2}{|r|}{ MSM } & \multicolumn{2}{|r|}{ BB } & \multicolumn{2}{|r|}{ FSW } & \multicolumn{2}{|r|}{ DU } & Total (ADJ) \\
\hline & & No & $\%$ & No & $\%$ & No & $\%$ & No & $\%$ & (\%) \\
\hline \multirow[t]{4}{*}{ Gender } & Male & 172 & $93 \%$ & 127 & $99 \%$ & 0 & $0 \%$ & 127 & $88 \%$ & $68.9 \%$ \\
\hline & Female & 1 & $1 \%$ & 0 & $0 \%$ & 152 & $98 \%$ & 17 & $12 \%$ & $30.6 \%$ \\
\hline & Transgender & 11 & $6 \%$ & 1 & $1 \%$ & 3 & $2 \%$ & 1 & $1 \%$ & $0.5 \%$ \\
\hline & Total & 184 & 100 & 128 & 100 & 155 & 100 & 145 & 100 & $100 \%$ \\
\hline Sexual & Heterosexual & 14 & $8 \%$ & 78 & $63 \%$ & 143 & $96 \%$ & 110 & $79 \%$ & $65.8 \%$ \\
\hline Orientation & Homosexual & 97 & $54 \%$ & 13 & $11 \%$ & 0 & $0 \%$ & 7 & $5 \%$ & $15.4 \%$ \\
\hline & Bisexual & 67 & $37 \%$ & 32 & $26 \%$ & 5 & $3 \%$ & 20 & $14 \%$ & $17.9 \%$ \\
\hline & Other & 1 & $1 \%$ & 0 & $0 \%$ & 1 & $1 \%$ & 2 & $1 \%$ & $0.9 \%$ \\
\hline & Total & 179 & 100 & 123 & & 149 & 100 & 139 & 100 & $100 \%$ \\
\hline Current marital & Single & 129 & $71 \%$ & 60 & $48 \%$ & 26 & $18 \%$ & 53 & $37 \%$ & $40.7 \%$ \\
\hline status & Living together & 13 & $7 \%$ & 19 & $15 \%$ & 21 & $14 \%$ & 17 & $12 \%$ & $11.7 \%$ \\
\hline & Married & 27 & $15 \%$ & 37 & $29 \%$ & 68 & $46 \%$ & 63 & $44 \%$ & $36.5 \%$ \\
\hline & $\mathrm{D} / \mathrm{S} / \mathrm{W}$ & 13 & $7 \%$ & 10 & $8 \%$ & 33 & $22 \%$ & 10 & $7 \%$ & $11.0 \%$ \\
\hline & Other & 0 & $0 \%$ & 0 & $0 \%$ & 0 & $0 \%$ & 0 & $0 \%$ & $0.0 \%$ \\
\hline & Total & 182 & 100 & 126 & 100 & 148 & 100 & 143 & 100 & $100 \%$ \\
\hline Employment & Student & 11 & $6 \%$ & 0 & $0 \%$ & 0 & $0 \%$ & 1 & $1 \%$ & $1.7 \%$ \\
\hline status & Not employed & 29 & $16 \%$ & 25 & $20 \%$ & 78 & $52 \%$ & 34 & $24 \%$ & $28.7 \%$ \\
\hline & Self-employed & 63 & $35 \%$ & 31 & $25 \%$ & 27 & $18 \%$ & 61 & $42 \%$ & $32.7 \%$ \\
\hline & Employed & 63 & $35 \%$ & 46 & $37 \%$ & 38 & $25 \%$ & 40 & $28 \%$ & $29.6 \%$ \\
\hline & Retired & 2 & $1 \%$ & 24 & $19 \%$ & 2 & $1 \%$ & 2 & $1 \%$ & $3.0 \%$ \\
\hline & Other & 12 & $7 \%$ & 0 & $0 \%$ & 6 & $4 \%$ & 6 & $4 \%$ & $4.3 \%$ \\
\hline & Total & 180 & $100 \%$ & 126 & $100 \%$ & 151 & $100 \%$ & 144 & $100 \%$ & $100 \%$ \\
\hline Level of & Pre-school & 3 & $2 \%$ & 1 & $1 \%$ & 3 & $2 \%$ & 3 & $2 \%$ & $1.8 \%$ \\
\hline education & Primary 1-5 & 11 & $6 \%$ & 13 & $10 \%$ & 29 & $19 \%$ & 15 & $11 \%$ & $11.7 \%$ \\
\hline & Completed 6-10 & 77 & $42 \%$ & 66 & $53 \%$ & 72 & $47 \%$ & 76 & $54 \%$ & $49.3 \%$ \\
\hline & Passed OL & 41 & $22 \%$ & 23 & $18 \%$ & 35 & $23 \%$ & 33 & $23 \%$ & $22.5 \%$ \\
\hline & Passed AL & 42 & $23 \%$ & 20 & $16 \%$ & 11 & $7 \%$ & 13 & $9 \%$ & $12.4 \%$ \\
\hline & Diploma & 5 & $3 \%$ & 1 & $1 \%$ & 1 & $1 \%$ & 1 & $1 \%$ & $1.2 \%$ \\
\hline & Degree & 5 & $3 \%$ & 0 & $0 \%$ & 1 & $1 \%$ & 0 & $0 \%$ & $0.8 \%$ \\
\hline & Other & 1 & $1 \%$ & 1 & $1 \%$ & 0 & $0 \%$ & 0 & $0 \%$ & $0.2 \%$ \\
\hline & Total & 185 & $100 \%$ & 125 & $100 \%$ & 152 & $100 \%$ & 141 & $100 \%$ & $100 \%$ \\
\hline District mostly & Anuradhapura & 26 & $15 \%$ & 0 & $0 \%$ & 12 & $8 \%$ & 13 & $9 \%$ & $9.2 \%$ \\
\hline lived during & Colombo & 78 & $44 \%$ & 24 & $19 \%$ & 66 & $44 \%$ & 69 & $49 \%$ & $43.4 \%$ \\
\hline the previous & Galle & 34 & $19 \%$ & 49 & $40 \%$ & 5 & $3 \%$ & 15 & $11 \%$ & $13.4 \%$ \\
\hline year & Gampaha & 32 & $18 \%$ & 22 & $18 \%$ & 32 & $21 \%$ & 35 & $25 \%$ & $21.6 \%$ \\
\hline & Hambantota & 1 & $1 \%$ & 0 & $0 \%$ & 0 & $0 \%$ & 0 & $0 \%$ & $0.1 \%$ \\
\hline & Kalutara & 7 & $4 \%$ & 20 & $16 \%$ & 1 & $1 \%$ & 0 & $0 \%$ & $2.6 \%$ \\
\hline & Kandy & 0 & $0 \%$ & 1 & $1 \%$ & 0 & $0 \%$ & 0 & $0 \%$ & $0.1 \%$ \\
\hline & Kurunegala & 1 & $1 \%$ & 0 & $0 \%$ & 3 & $2 \%$ & 0 & $0 \%$ & $0.6 \%$ \\
\hline & Matara & 0 & $0 \%$ & 0 & $0 \%$ & 1 & $1 \%$ & 0 & $0 \%$ & $0.2 \%$ \\
\hline & Puttlam & 0 & $0 \%$ & 8 & $6 \%$ & 3 & $2 \%$ & 0 & $0 \%$ & $1.1 \%$ \\
\hline & Ratnapura & 0 & $0 \%$ & 0 & $0 \%$ & 26 & $17 \%$ & 10 & $7 \%$ & $7.4 \%$ \\
\hline & Missing data & 0 & $0 \%$ & 0 & $0 \%$ & 1 & $1 \%$ & 0 & $0 \%$ & $0.2 \%$ \\
\hline & Total & 179 & $100 \%$ & 124 & $100 \%$ & 150 & $100 \%$ & 142 & $100 \%$ & $100 \%$ \\
\hline
\end{tabular}

$A D J=$ Adjusted summary measure for all the groups 
Multiple answer questions were used to describe the preferred method of access for an HIV test, preferred biological sample and preferred turnaround time for the test results. It shows that these groups generally prefer

community testing, testing by outreaching STD clinic staff and outreaching healthcare workers.

However, accessing to a STD clinic for an HIV test is preferred only by $10 \%$ of respondents. Most preferred sampling methods were oralfluid test and finger prick tests. Majority preferred to receive the test result just after the test. (Table 4)

Oral-fluid HIV test results: All the study participants were offered the oral-fluid rapid
HIV test and overall $98.5 \%$ accepted the test. The prevalence of reactive test results in the sample was $1.3 \%$ ( 7 cases or reactive tests). Individuals with reactive HIV test results were referred to the nearest STD clinic to undergo the series of HIV test in the national algorithm for HIV diagnosis. Out of the seven reactive test results, one was found to be confirmed positive for HIV. (Table 5)

Oral-fluid rapid HIV test identified 7 reactive patients and sent them to STD clinic for HIV confirmation. However, only one was confirmed to have HIV infection among the MSM group.

Table 4: Preferred method of access for an HIV test, preferred biological sample and preferred turnaround time by the type of peer group

\begin{tabular}{|c|c|c|c|c|c|c|}
\hline \multirow[t]{2}{*}{ Variable } & \multirow[t]{2}{*}{ Variable level } & $\begin{array}{r}\text { MSM } \\
(n=185)\end{array}$ & $\begin{array}{r}\text { BB } \\
(n=128)\end{array}$ & $\begin{array}{r}\text { FSW } \\
(n=155)\end{array}$ & $\begin{array}{r}D U \\
(n=146)\end{array}$ & $\begin{array}{r}\text { Total } \\
\text { sample }\end{array}$ \\
\hline & & No (\%) & No (\%) & No (\%) & No (\%) & (ADJ) \\
\hline \multirow{7}{*}{$\begin{array}{l}\text { Preferred } \\
\text { method of } \\
\text { access for an } \\
\text { HIV test }\end{array}$} & Going to an STD clinic & $18(10 \%)$ & $13(10 \%)$ & $13(8 \%)$ & $18(12 \%)$ & $10.5 \%$ \\
\hline & STD clinic staff visiting our place & $92(50 \%)$ & $58(45 \%)$ & $92(59 \%)$ & $63(43 \%)$ & $49.0 \%$ \\
\hline & Testing by an outreach healthcare worker & $58(31 \%)$ & $29(23 \%)$ & $42(27 \%)$ & $40(27 \%)$ & $27.8 \%$ \\
\hline & HIV testing in a community friendly centre & $34(18 \%)$ & $9(7 \%)$ & $19(12 \%)$ & $23(16 \%)$ & $14.6 \%$ \\
\hline & Testing by the Peer Educator at your place & $63(34 \%)$ & $81(63 \%)$ & $68(44 \%)$ & $83(57 \%)$ & $49.0 \%$ \\
\hline & Other (Specify) & $11(6 \%)$ & $2(2 \%)$ & $1(1 \%)$ & $1(1 \%)$ & $1.9 \%$ \\
\hline & Not answered or missing values & $6(3 \%)$ & $1(1 \%)$ & $3(2 \%)$ & $2(1 \%)$ & $1.8 \%$ \\
\hline \multirow{5}{*}{$\begin{array}{l}\text { Preferred } \\
\text { method of } \\
\text { sampling }\end{array}$} & Testing by drawing a sample of blood & $16(9 \%)$ & $2(2 \%)$ & $6(4 \%)$ & $12(8 \%)$ & $6.6 \%$ \\
\hline & Testing by finger prick & $26(14 \%)$ & $17(13 \%)$ & $12(8 \%)$ & $13(9 \%)$ & $10.2 \%$ \\
\hline & Testing by using oral fluid & $159(86 \%)$ & $108(84 \%)$ & $144(93 \%)$ & $127(87 \%)$ & $88.0 \%$ \\
\hline & Other (Specify) & $1(1 \%)$ & $1(1 \%)$ & $0(0 \%)$ & $4(3 \%)$ & $1.3 \%$ \\
\hline & Not answered or missing values & $8(4 \%)$ & $2(2 \%)$ & $5(3 \%)$ & $2(1 \%)$ & $2.5 \%$ \\
\hline \multirow{4}{*}{$\begin{array}{l}\text { When would } \\
\text { you prefer to } \\
\text { get the result } \\
\text { of the test }\end{array}$} & Within 1 week & $3(2 \%)$ & $4(3 \%)$ & $10(7 \%)$ & $5(3 \%)$ & $3.9 \%$ \\
\hline & Within 2-3 days & $13(7 \%)$ & $16(13 \%)$ & $12(8 \%)$ & $10(7 \%)$ & $7.9 \%$ \\
\hline & Just after testing & $159(91 \%)$ & $104(84 \%)$ & $128(85 \%)$ & $130(90 \%)$ & $88.3 \%$ \\
\hline & Total & $175(100 \%)$ & $124(100 \%)$ & $150(100 \%)$ & $145(100 \%)$ & $100(100 \%)$ \\
\hline
\end{tabular}

Table 5: Results of the oral-fluid rapid HIV test

\begin{tabular}{|c|c|c|c|c|c|c|c|c|c|c|}
\hline & \multirow[t]{2}{*}{ Category } & \multicolumn{2}{|r|}{ MSM } & \multicolumn{2}{|r|}{ BB } & \multicolumn{2}{|r|}{ FSW } & \multicolumn{2}{|r|}{ DU } & \multirow{2}{*}{$\begin{array}{l}\text { Total } \\
\text { (ADJ) }\end{array}$} \\
\hline & & No. & $\%$ & No. & $\%$ & No. & $\%$ & No. & $\%$ & \\
\hline \multirow{5}{*}{$\begin{array}{l}\text { Oral- } \\
\text { fluid } \\
\text { rapid } \\
\text { HIV test } \\
\text { result }\end{array}$} & Number tested & 180 & $\begin{array}{r}97 \% \\
(n=185)\end{array}$ & 128 & $\begin{array}{r}100 \% \\
(n=128)\end{array}$ & 151 & $\begin{array}{r}97 \% \\
(n=155)\end{array}$ & 145 & $\begin{array}{r}99 \% \\
(\mathrm{~N}=146)\end{array}$ & $98.4 \%$ \\
\hline & Reactive & 3 & $2 \%$ & 1 & $1 \%$ & 0 & $0 \%$ & 3 & $2 \%$ & $1.3 \%$ \\
\hline & Non-reactive & 175 & $97 \%$ & 127 & $99 \%$ & 151 & $100 \%$ & 142 & $98 \%$ & $98.4 \%$ \\
\hline & Invalid & 2 & $1 \%$ & 0 & $0 \%$ & 0 & $0 \%$ & 0 & $0 \%$ & $0.3 \%$ \\
\hline & Total & 180 & $100 \%$ & 128 & $100 \%$ & 151 & $100 \%$ & 145 & $100 \%$ & \\
\hline & $\begin{array}{l}\text { Number confirmed } \\
\text { with HIV }\end{array}$ & 1 & $1 \%$ & 0 & $0 \%$ & 0 & $0 \%$ & 0 & $0 \%$ & $0.1 \%$ \\
\hline
\end{tabular}




\section{Acceptability of oral-fluid rapid HIV test (OraQuick) among different KP groups}

The following table describes the study participants' feedback on the level of satisfaction towards the oral fluid rapid HIV testing process. The feedback given to individual statements showed that participants were satisfied with the oral-fluid rapid test. However, some respondents had felt a pressure to get the test done $(18 \%)$ and another $13 \%$ still complained that they had to wait too long even for the oral-fluid rapid test. Furthermore, about $6 \%$ did not like the test. About one fourth of MSM (28\%) and BB (27\%) believed that this type of HIV test is a barrier to receive other services from STD clinics. (Table 6)

Table 6: Acceptability of oral-fluid rapid HIV test

\begin{tabular}{|c|c|c|c|c|c|c|c|c|c|c|}
\hline \multicolumn{11}{|c|}{ Acceptability of oral fluid-rapid HIV test } \\
\hline \multirow[t]{2}{*}{ Statement } & \multirow[t]{2}{*}{$\begin{array}{c}\text { Agree/ } \\
\text { Disagree }\end{array}$} & \multicolumn{2}{|c|}{$\begin{array}{r}\text { MSM } \\
(\mathrm{n}=185) \\
\end{array}$} & \multicolumn{2}{|r|}{$\begin{array}{r}\text { BB } \\
(n=128)\end{array}$} & \multicolumn{2}{|c|}{$\begin{array}{r}\text { FSW } \\
(n=155)\end{array}$} & \multicolumn{2}{|c|}{$\begin{array}{r}\text { DU } \\
(n=146)\end{array}$} & \multirow{2}{*}{$\begin{array}{r}\text { Tota } \\
\text { sample } \\
\text { (ADJ) }\end{array}$} \\
\hline & & No & $\%$ & No & $\%$ & No & $\%$ & No & $\%$ & \\
\hline \multirow{2}{*}{$\begin{array}{l}\text { I would recommend this test to } \\
\text { others as a good test }\end{array}$} & Agree & 183 & $99 \%$ & 128 & $100 \%$ & 153 & $99 \%$ & 145 & $99 \%$ & $99.1 \%$ \\
\hline & Disagree & 0 & $0 \%$ & 0 & $0 \%$ & 1 & $1 \%$ & 0 & $0 \%$ & $0.2 \%$ \\
\hline \multirow{2}{*}{$\begin{array}{l}\text { I was satisfied with the test that I } \\
\text { received today }\end{array}$} & Agree & 183 & $99 \%$ & 128 & $100 \%$ & 152 & $98 \%$ & 145 & $99 \%$ & $99.0 \%$ \\
\hline & Disagree & 0 & $0 \%$ & 0 & $0 \%$ & 1 & $1 \%$ & 1 & $1 \%$ & $0.5 \%$ \\
\hline \multirow{2}{*}{$\begin{array}{l}\text { I felt pressured into getting the } \\
\text { HIV test today }\end{array}$} & Agree & 58 & $31 \%$ & 30 & $23 \%$ & 26 & $17 \%$ & 14 & $10 \%$ & $17.7 \%$ \\
\hline & Disagree & 120 & $65 \%$ & 98 & $77 \%$ & 128 & $83 \%$ & 131 & $90 \%$ & $81.0 \%$ \\
\hline \multirow[t]{2}{*}{ I do not like this type of HIV test } & Agree & 30 & $16 \%$ & 5 & $4 \%$ & 6 & $4 \%$ & 4 & $3 \%$ & $6.2 \%$ \\
\hline & Disagree & 151 & $82 \%$ & 122 & $95 \%$ & 147 & $95 \%$ & 140 & $96 \%$ & $92.3 \%$ \\
\hline \multirow{2}{*}{$\begin{array}{l}\text { I had to wait too long for my HIV } \\
\text { test result }\end{array}$} & Agree & 37 & $20 \%$ & 12 & $9 \%$ & 22 & $14 \%$ & 13 & $9 \%$ & $12.8 \%$ \\
\hline & Disagree & 147 & $79 \%$ & 116 & $91 \%$ & 131 & $85 \%$ & 133 & $91 \%$ & $86.7 \%$ \\
\hline \multirow{2}{*}{$\begin{array}{l}\text { This HIV test is a barrier to } \\
\text { receive other services from the } \\
\text { STD clinic }\end{array}$} & Agree & 51 & $28 \%$ & 34 & $27 \%$ & 14 & $9 \%$ & 20 & $14 \%$ & $16.9 \%$ \\
\hline & Disagree & 131 & $71 \%$ & 94 & $73 \%$ & 139 & $90 \%$ & 124 & $85 \%$ & $81.8 \%$ \\
\hline \multirow{2}{*}{$\begin{array}{l}\text { Overall, I felt that the test done } \\
\text { today was private and } \\
\text { confidential }\end{array}$} & Agree & 165 & $89 \%$ & 122 & $95 \%$ & 148 & $95 \%$ & 133 & $91 \%$ & $92.2 \%$ \\
\hline & Disagree & 18 & $10 \%$ & 5 & $4 \%$ & 6 & $4 \%$ & 13 & $9 \%$ & $7.3 \%$ \\
\hline \multirow{2}{*}{$\begin{array}{l}\text { I felt that my HIV test result was } \\
\text { told to me in a private way }\end{array}$} & Agree & 179 & $97 \%$ & 127 & $99 \%$ & 152 & $98 \%$ & 146 & $100 \%$ & $98.7 \%$ \\
\hline & Disagree & 5 & $3 \%$ & 1 & $1 \%$ & 1 & $1 \%$ & 0 & $0 \%$ & $0.9 \%$ \\
\hline \multirow{2}{*}{$\begin{array}{l}\text { I understand the meaning of my } \\
\text { HIV test result }\end{array}$} & Agree & 184 & $99 \%$ & 128 & $100 \%$ & 154 & $99 \%$ & 146 & $100 \%$ & $99.7 \%$ \\
\hline & Disagree & 0 & $0 \%$ & 0 & $0 \%$ & 0 & $0 \%$ & 0 & $0 \%$ & $0.0 \%$ \\
\hline \multirow{2}{*}{$\begin{array}{l}\text { The information I was given } \\
\text { about HIV testing was } \\
\text { satisfactory }\end{array}$} & Agree & 183 & $99 \%$ & 127 & $99 \%$ & 154 & $99 \%$ & 146 & $100 \%$ & $99.5 \%$ \\
\hline & Disagree & 1 & $1 \%$ & 0 & $0 \%$ & 0 & $0 \%$ & 0 & $0 \%$ & $0.1 \%$ \\
\hline
\end{tabular}

\section{Overall satisfaction of the oral fluid rapid HIV} test

As the final evaluation on the level of satisfaction, respondents were asked to rate the overall satisfaction of the oral-fluid rapid HIV test. Following table shows the ratings given by peer type. Overall satisfaction about the oral-fluid rapid HIV test had been rated "Good", "Very good" or "Excellent" by over $97 \%$ of respondents. 
Table 7: Overall satisfaction

\begin{tabular}{|c|c|c|c|c|c|c|c|c|c|c|}
\hline \multicolumn{11}{|l|}{ Satisfaction } \\
\hline & \multirow[t]{2}{*}{ Levels } & \multicolumn{2}{|r|}{ MSM } & \multicolumn{2}{|r|}{ BB } & \multicolumn{2}{|r|}{ FSW } & \multicolumn{2}{|r|}{ DU } & \multirow{2}{*}{$\begin{array}{l}\text { Total } \\
\text { (ADJ) }\end{array}$} \\
\hline & & No & $\%$ & No & $\%$ & No & $\%$ & No & $\%$ & \\
\hline \multirow{5}{*}{$\begin{array}{l}\text { Overall, how is your } \\
\text { satisfaction about } \\
\text { this oral fluid HIV } \\
\text { test (OraQuick test) }\end{array}$} & Poor/Fair & 5 & $3 \%$ & 1 & $1 \%$ & 1 & $1 \%$ & 1 & $1 \%$ & $1.2 \%$ \\
\hline & Good & 35 & $19 \%$ & 24 & $19 \%$ & 47 & $31 \%$ & 15 & $10 \%$ & $18.5 \%$ \\
\hline & Very Good & 88 & $48 \%$ & 21 & $17 \%$ & 39 & $26 \%$ & 50 & $34 \%$ & $33.6 \%$ \\
\hline & Excellent & 55 & $30 \%$ & 80 & $63 \%$ & 65 & $43 \%$ & 79 & $54 \%$ & $46.8 \%$ \\
\hline & Total & 183 & $100 \%$ & 126 & $100 \%$ & 152 & $100 \%$ & 145 & $100 \%$ & $100 \%$ \\
\hline
\end{tabular}

\section{Discussion}

The national steering committee formed to introduce the oral-fluid rapid HIV antibody test wanted to look at the acceptability of the test among key populations before being introduced as a community based test (CBT). Test sensitivity and specificity was a major concern at the beginning. However, the Thailand version of this oral-fluid test (OraQuick) has $100 \%$ sensitivity and $99.87 \%$ specificity according to the manufacturers brochure enclosed with the product package. There were no results of any validation in the country. This study's main target was not to detect new cases but to comprehend the acceptability of the oral-fluid HIV test as a community based test among key populations, which can mainly be introduced at community settings such as drop-in centres and other forms of community locations in order to reduce the testing gap.

Different types of Oral-fluid rapid HIV tests are available and its technologies are evolving. Therefore, the steering committee mainly focused at assessing the acceptability of the test hoping to replace high quality oralfluid test in future in the country as a community based HIV test. The study showed high acceptability for an oral-fluid test of this nature and over $97 \%$ expressed satisfaction regarding the test and the testing procedure done by the trained community testers. Furthermore, participants expressed their willingness to undergo the test done by both community testers and out-reaching healthcare workers. In contrast, the access to a STD clinic is accepted only by $10 \%$, which reflects the need for an alternative method of testing. In this high acceptable situation, the test can also be introduced as a self-test of HIV.

\section{Conclusion}

Majority of members of the key populations has accepted oral-fluid rapid HIV test. Rating of satisfaction as good, very good and excellent were taken as expression of satisfaction and $97 \%$ of MSMs and $99 \%$ of $B B$, 99\% of FSW and $99 \%$ of DUs were overall satisfied with the test. However, some respondents had felt a pressure to get the test done $(18 \%)$ and another $13 \%$ still complained that they had to wait too long even for the oral-fluid rapid test. Furthermore, about 6\% did not like the test. About one fourth of MSM (28\%) and BB (27\%) believed that this type of HIV test is a barrier to receive other services from STD clinics. The oral-fluid rapid HIV test can be introduced to key populations an community based HIV test based on the acceptability and satisfaction expressed.

\section{References}

1. National STD/AIDS Control Programme. Annual Report 2015. Colombo: Ministry of Health, National STD/AIDS Control Programme; 2016.

2. World Health Organization, Guideline development group. Consolidated guideline on HIV testing services Geneva: World Health Organization; 2015.

3. OraSure Technologies Inc. Product Brochure. ; 2014.

4. NSACP. Annual Report. Colombo:; 2017. 